\title{
Cell tracking using multimodal imaging
}

\author{
Mangala Srinivas ${ }^{a}$, Ignacio Melerob, Eckhart Kaempgenc, \\ Carl G. Figdor ${ }^{\mathrm{a}}$ and I. Jolanda M. de Vries ${ }^{\mathrm{a} *}$
}

\begin{abstract}
In vivo imaging plays a key role in cell tracking, particularly for the optimization of cellular therapeutics. A recent trend is to use more than one imaging modality (multimodality imaging) for this purpose. There are several advantages to multimodal cell tracking, particularly the corroboration of data obtained using a new imaging agent or technique with an established one, and the ability to glean complementary information from a single experiment. In this review, we examine the different types of labels and imaging strategies used in the literature for multimodal cell tracking, and discuss the pros and cons of these approaches, with a focus on MRI. Despite many efforts and novel technologies, we still have to face situations where current imaging methods are simply not sensitive enough and new labeling strategies are hampered by the lack of approved reagents. Finally, we examine new in vitro and preclinical developments, which have the potential to tackle unresolved challenges in in vivo multimodal imaging. Copyright @ 2013 John Wiley \& Sons, Ltd.
\end{abstract}

Keywords: cell tracking; in vivo imaging; multimodal; MRI; fluorescence; SPECT; PET; bioluminescence

\section{INTRODUCTION}

Multimodal imaging is the use of more than one imaging modality for a specific purpose, in this case, cell tracking. Cell tracking consists of following specific cells in vivo; this is often in terms of their localization, but can also be in terms of their fate, functionality or differentiation. Cell tracking using imaging has several advantages, such as the noninvasive nature of imaging which can allow longitudinal follow-up of cells, and the ability to acquire specific information such as about the numbers of cells in a region of interest, their viability and their functionality. Noninvasive imaging is also applicable to humans. For all these reasons, imaging plays a key role in the optimization of cellular therapeutics (1). Multimodal imaging is particularly powerful in that it allows for comprehensive monitoring of labeled cells, as the strengths of the different imaging modalities can be maximized. Multimodal imaging can be done using a single label or tracer that is visible using different imaging modalities, or a combination of imaging labels. The imaging modalities typically applied to cell tracking include whole body scintigraphy, magnetic resonance imaging (MRI), positron emission tomography (PET), fluorescence imaging (FLI), bioluminescence (BLI) and single photo emission computed tomography (SPECT).

SPECT, PET and scintigraphy require the use of radioactive labels. For example, SPECT and scintigraphy are commonly done using ${ }^{111} \mathrm{In}$ and ${ }^{99 \mathrm{~m}} \mathrm{Tc}$. These have half-lives of up to 3 days, dependent on the isotope. PET tracers, often ${ }^{18} \mathrm{~F}$ analogs of glucose or thymidine, are much more short-lived, with half-lives in the order of hours. Furthermore, all these agents result in radiation exposure to subjects and thus their dosage and repeated use is limited and tightly regulated. However, nuclear medicine imaging techniques such as these can be very sensitive and yield quantitative information on label content. MRI, on the other hand, does not require the use of radiolabels. Instead, cells are labeled with iron oxide nano- or microparticles, or other metals such as gadolinium (Gd) or manganese (Mn). MR imaging works on the ${ }^{1} \mathrm{H}$ nucleus, present abundantly in biological tissues, particularly in the form of mobile water, resulting in exquisite anatomic detail. Contrast agents result in the labeled cells presenting as hyperintense ( $T_{1}$ agents) or hypointense regions ( $T_{2}$ and $T_{2}^{*}$ agents) on appropriately weighted MR images. Imaging using certain iron oxide agents can be very sensitive, even up to single cell imaging (2). Note that the use of MR contrast agents is also closely regulated, and they are not officially approved as cell labels. MR reporter genes have also been developed, where the genes are typically involved in intracellular iron levels (3). However, quantification of cell numbers with contrast agents can be difficult. Recently, much work has focused on labeling cells with ${ }^{19} \mathrm{~F}$ agents for cell tracking. ${ }^{19} \mathrm{~F} \mathrm{MRI}$ is quantitative, but suffers from sensitivity issues and is still in preclinical testing (4). Finally, the light-based in vivo imaging modalities, FLI and BLI, are perhaps the most common owing to their relative ease of use. However, the techniques are limited by the penetration depth of light, and are thus most often used in preclinical models, particularly nude mice, with limited potential for translational application to humans. The use of fluorescent agents to label cells is very well established, for example in microscopy and flow cytometry. For these reasons, fluorescent agents are most often combined with imaging agents for MRI, SPECT or PET. BLI is similar to $\mathrm{FLI}$, except that it requires the expression of an enzyme, luciferase, which catalyzes the

\footnotetext{
* Correspondence to: J. M. de Vries, Nijmegen Centre for Molecular Life Sciences, Radboud University Nijmegen Medical Centre, Department of Tumor Immunology, Nijmegen, The Netherlands. Email: J.deVries@ncmls.ru.nl

a M. Srinivas, C. G. Figdor, I. J. M. de Vries

Nijmegen Centre for Molecular Life Sciences, Radboud University Nijmegen Medical Centre, Department of Tumor Immunology, Nijmegen, The Netherlands

b I. Melero

University of Navarra, CIMA, CUV and Medica School, Pamplona, Spain

c E. Kaempgen

University Hospital Erlangen, Dept. of Dermatology, Erlangen, Germany
} 


\begin{abstract}
Biography
Mangala Srinivas did her B.Sc. (Honours) at the National University of Singapore. From there, she went on to complete her Ph.D. at Carnegie Mellon University in Pittsburgh, USA. She has since been working at the Dept. of Tumor Immunology at the Nijmegen Center for Molecular Life Sciences (The Netherlands). Mangala's initial work during

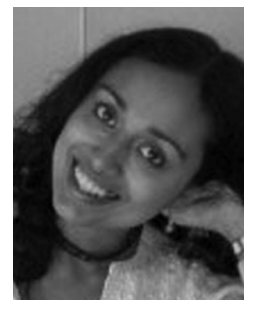
her Ph.D. involved the development and application of $19 \mathrm{~F}$ magnetic resonance imaging (MRI) for in vivo cell tracking. Her present work involves the development and application of multimodal imaging agents to various applications, both clinical and preclinical. Mangala is currently funded by a personal VENI grant from the Netherlands Institute for Scientific Research (NWO). She has recently been awarded a Starting Grant by the European Research Council (ERC).
\end{abstract}

\begin{abstract}
Biography
Ignacio Melero graduated as MD from the University of Navarra School of Medicine and was trained as a resident in clinical immunology at Hospital de la Princesa (Universidad Autonoma de Madrid). He also earned a PhD degree working with Dr. Miguel Lopez Botet pioneering the characterization of NK cell inhibitory receptors. In 1994 he moved to Seattle (USA) where he worked with Karl E. Helström and Lieping Chen in tumor immunology. His work was devoted to study T cell ignorance of tumor antigens and the role of costimulation in mouse models of cancer. His studies of that time on CD137mediated stimulation of curative antitumor immune responses have received much attention. In 1998 he returned to Pamplona (University of Navarra), where he works at the Clinica Universitaria and at the investigation centre (CIMA). He was appointed full professor of Immunology in 2004. His current areas of research are focused on from bench to bedside translational research with cell, gene and monoclonal antibody-mediated therapies for cancer.
\end{abstract}

\section{Biography \\ Dr. Kaempgen has been working in the field of Dendritic Cells since more than 20 years and continuously contributed to both, basic research on the immuno- biology of DCs and translational re- search resulting in $D C$ based treatment of tumor patients ( $>100$ peer reviewed publications). He received his MD in 1987 at the medical school of the LMU

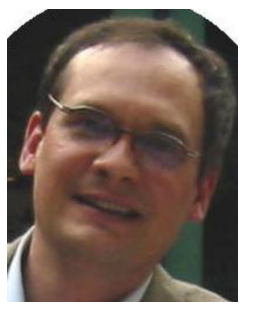 Munich and, before starting his derma- tology fellowship at the Univ. of Würzburg (Günter Burg, Eva Bröcker) in 1990, was trained as research associate at the Depts. of Immunology, Munich (Gert Riethmüller) and Dermatology, Univ. of Innsbruck (Gerold Schuler, Peter}

Fritsch). From the very first beginning Dr. Kaempgen was involved in the development of today's standard method to generate human DCs from peripheral blood monocytes and especially strategies to load DC with tumor antigens by RNA transfection, which was developed in close cooperation with Eli Gilboa at the Duke University, Durham. Following a position as Director of Immunology, Merix* Inc., Durham, NC Dr. Kaempgen in 2003 became Associate Professor for Strategies of Cellular Immunotherapy at the Dep. Dermatology, Univ. of Erlangen (head: Gerold Schuler), where he currently is the responsible senior dermatologist for skin tumor patients and heading the interdisciplinary melanoma tumor board. Starting September on 2013 Dr. Kaempgen will be working as a partner at the dermatologikum in berlin (www. dermatologikum-berlin.de).

\section{Biography}

Carl Figdor (Radboud University Medical Centre Nijmegen) obtained his Masters from the University of Utrecht, and his PhD degree from the University of Amsterdam working at the Netherlands Cancer Institute, where he was tenured in 1985 and started his own research group on Tumor Immunology. In 1992 Carl Figdor became Professor in Cell Biophysics at the University of Twente, and in 1994 he moved to Nijmegen to start a new department on Tumor Immunology as a Professor in Immunology. From 2001 - 2011 he served as the first scientific director of the Nijmegen Centre for Molecular Life Sciences (NCMLS). Carl Figdor is a member of the Royal Netherlands Academy of Arts and Sciences and is the recipient of several awards, including the Dutch Spinoza Award in 2006, and the KWO award from the Dutch Cancer Society in 2009. He obtained an ERC Advanced Investigator grant in 2011.

\begin{abstract}
Biography
Jolanda de Vries is a Professor at the Department of Tumor Immunology at the Nijmegen Centre for Molecular Life Sciences (NCMLS) at the Radboud University Medical Center. She was one of the pioneers in the translation of dendritic cell (DC) biology into potential clinical application, initiating the first clinical phase I/II studies in which patients were vaccinated with DCs loaded with tumor-specific peptides in 1997. Jolanda was also the first to apply MRI to clinical cell tracking in 2005. More recently, she has applied PET to study DC functionality in patients after transfer. Clinical trials involving DC vaccination and a combination of imaging modalities to effectively monitor the cells in patients are in process.
\end{abstract}


conversion of a substrate (luciferin to oxyluciferin) with the release of a photon. The photon released is detected. Typically, cells express luficerase as a reporter gene and luciferin is injected intravenously. Thus, this technique requires that the relevant cells be viable for imaging, not simply the presence of label. Reporter genes can also be used to label cells for PET imaging where a ${ }^{18} \mathrm{~F}$-labeled precursor is metabolized and retained by the gene-expressing cells (5).

\section{ROLE OF MULTIMODAL IMAGING}

\subsection{Validation}

One of the main advantages of multimodal imaging is that an established imaging modality or technique can be combined with a more experimental one. Typically FLI and fluorescencebased techniques, such as microscopy, histology and flow cytometry, function as the established modality and can be considered the gold standard. Fluorescent dyes are well-characterized and relatively easy to add to imaging agents, for example, simply dissolved in a surfactant with liposomal agents or covalently bound to particulate agents. Alternatively, some studies use transgenic cells that express a fluorescent protein, or luciferase for BLI or a reporter enzyme for PET. These can be constitutionally expressed or used as a reporter gene for a given biofunction. In either case, luminescence indicates live and functional cells, and not simply the presence of imaging label, when the expressed luciferase is ATP-dependent. A recent example demonstrated the power of this combination (18): mesenchymal stem cells were transfected with a luciferase vector and labeled with either superparamagnetic iron oxide (SPIO) or Gd for MRI. The authors found that SPIO signal persisted even after complete loss of BLI signal. SPIO signal persisted longer than Gd signal. This demonstrates that simply the presence or absence of signal owing to a contrast agent may not indicate live cells. Often, dead cells and their material (including some imaging agents) can be phagocytosed by macrophages and thus indirectly label these cells. These factors must be taken into account when interpreting in vivo image data.

\subsection{Complementary Information}

The use of another scientific technique, with a more established label and protocol, is essential to develop and apply a new label and/or imaging modality. For example, histology or microscopy

a
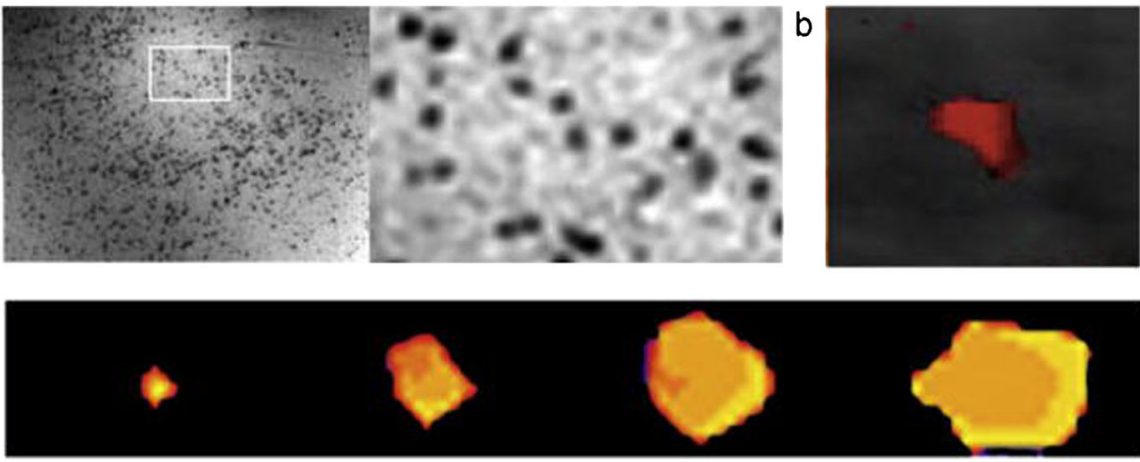

d

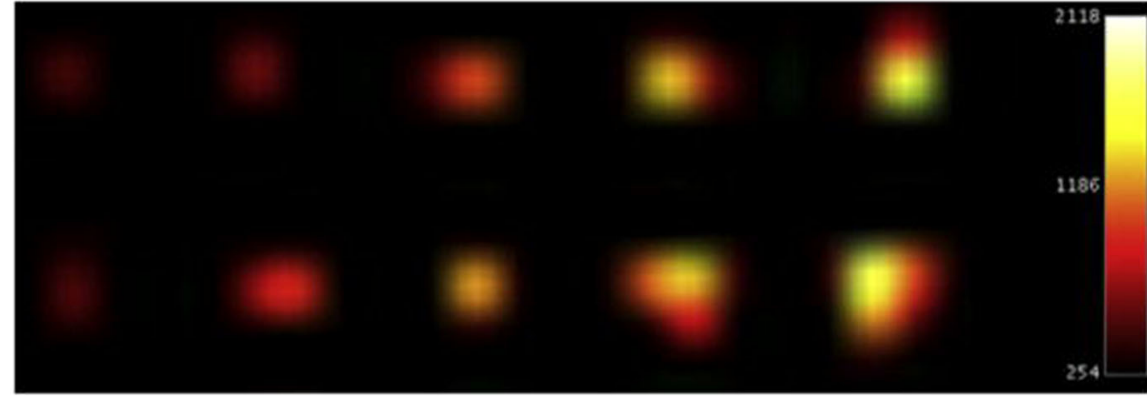

e

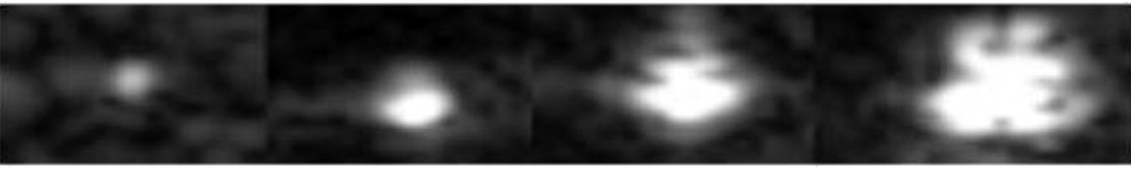

f
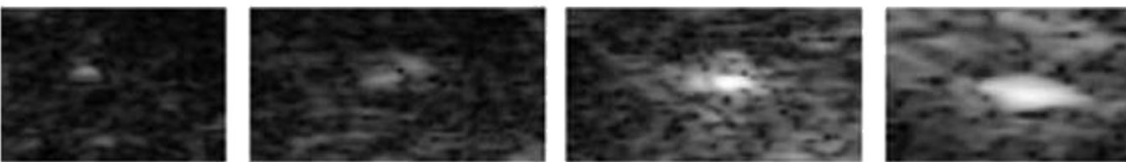

Figure 1. Multimodal imaging of labeled human islets. The islets were labeled with a fluorinated emulsion, where the fluorocarbon used also contains a Br atom which allows for Computed Topography (CT) contrast. (a) Shows ${ }^{1} \mathrm{H}$ MRI detection of iron-labeled islets, at 50 islets $/ \mathrm{ml}$ gel. The dark spots represent single islets (inset). (b) CT image of 10 fluorine-labeled islets. (c) ${ }^{19} \mathrm{~F}$ MR imaging of labeled fluorine-labeled islets, with a phantom containing 10, 50, 100 and 200 islets at high field strength. (d) Lower field strength imaging of fluorine-labeled islets with 500, 1000, 2000, 3000 and $4000 \mu \mathrm{g}$ of fluorocarbon (top), and 500, 1000, 1500, 2000 and 2500 fluorine-labeled islets (bottom). (e) Ultrasound images of fluorine-labeled islets in a phantom with 10,50, 100 and 200 islets. (f) In vivo ultrasound images of fluorine-labeled islets transplanted intramuscularly in a nude mouse, at 1,5 10 and 25 islets per injection. Figure reproduced from Barnett et al. (7), with permission. 
Table 1. Representative list of the different combinations of in vivo multimodal imaging for cell tracking used in the literature. Agent refers to the type of label used, for example, liposomes or molecular constructs

\begin{tabular}{|c|c|c|c|}
\hline Agent & Cell type & Imaging modalities & Reference \\
\hline Reporter gene & Transfected tumor cell & FLI, MRI, PET & (6) \\
\hline Emulsion & Pancreatic islets & FLI, MRI, CT, ultrasound & (7) \\
\hline Gold nanoparticles, Gd chelates & Pancreatic islets & MRI, CT, US & (8) \\
\hline Iron oxide, PET tracer & Stem cells & MRI, PET & (9) \\
\hline $\begin{array}{l}\text { MicroRNA-targeted magnetic } \\
\text { fluorescence nanoparticles }\end{array}$ & Neuronal stem cells & MRI, FLI & (10) \\
\hline $\begin{array}{l}\text { eGFP and luciferase expressing cells } \\
\text { labeled with iron oxide }\end{array}$ & Transgenic murine stromal cells & FLI, BLI, MRI & $(11)$ \\
\hline SPIO conjugated to ${ }^{111}$ In & Tumor cell line & MRI, SPECT & $(12)$ \\
\hline Functionalized silica nanoparticles & Immune cells & FLI, MRI, PET & (13) \\
\hline PEGylated complex & Stem cells & MRI, luminescence & (14) \\
\hline Molecular complex & & MRI, CT, luminescence & $(15)$ \\
\hline Particles & & BLI, PET, MRI, FLI & (16) \\
\hline Antibodies & & BLI, scintigrapy & (17) \\
\hline
\end{tabular}

Table 2. A general summary of the main issues that arise with multimodal imaging for cell tracking, and their common solutions

\begin{tabular}{|ll|}
\hline Issue & \multicolumn{1}{c}{ Solution } \\
\hline $\begin{array}{l}\text { Imaging often detects only the } \\
\text { presence of label, whether or not it is in the relevant cells } \\
\text { Effect of label on cells, particularly long-lived cells }\end{array}$ & $\begin{array}{l}\text { Reporter genes, or coupling to a second } \\
\text { imaging agent that is known to be cell-specific } \\
\text { More extensive testing of labeled cells, } \\
\text { including specific functionality assays }\end{array}$ \\
$\begin{array}{l}\text { Difficulties in image registration with different imaging modalities, } \\
\text { particularly with deformable tissues }\end{array}$ & $\begin{array}{l}\text { Various strategies have been developed, } \\
\text { such as subject immobilization, addition of references, } \\
\text { computer algorithms, and the use of hybrid scanners }\end{array}$ \\
$\begin{array}{l}\text { Cost and increased imaging time } \\
\text { Discrepancy between data from different imaging modalities }\end{array}$ & $\begin{array}{l}\text { The introduction of hybrid scanners can reduce } \\
\text { imaging time and cost }\end{array}$ \\
$\begin{array}{l}\text { These typically arise owing to differences in } \\
\text { more frequent use of anesthetics in preclinical studies }\end{array}$ & $\begin{array}{l}\text { sensitivity to cell viability or functionality } \\
\text { between the labels }\end{array}$ \\
$\begin{array}{l}\text { Complex anatomy and organ movement (bone, bone marrow, } \\
\text { lymph nodes, heart, lung) }\end{array}$ & $\begin{array}{l}\text { Hybrid scanners where possible, and } \\
\text { careful planning is necessary }\end{array}$ \\
\hline
\end{tabular}

has often been used as the 'established' technique to confirm in vivo image data. Histology can only be performed at the endpoint of an in vivo study, and is thus often supplemented or even replaced by FLI. Thus, most preclinical imaging agents contain a fluorescent component. Confocal microscopy is also typically used to study intracellular localization, although this can also be done with electron microscopy with agents such as iron oxides or quantum dots.

Other combinations of imaging modalities are used to yield different types of information. For example, MRI can be used for localization, together with scintigraphy or SPECT for quantification of cells labeled with both SPIO and radioactive indium isotopes. This has been done clinically to track dendritic cells in melanoma patients (19). More recently, such trials have been combined with PET, as PET can give longitudinal data on cell functionality (20).
The ability of multimodal imaging to yield complementary information is exemplified in a protocol designed to study stem cell implantation (11); BLI was used to assess cell survival, MRI for localization and post-mortem histology to validate the in vivo imaging results. In this example, the cells and the MRI label both had different fluorescent dyes to allow exact localization of the MRI agent using microscopy.

\subsection{Labeling Strategies}

Multimodal imaging requires that cells are labeled with imaging agents detectable by more than one imaging modality. However, this can mean a single agent, or a combination of chemically distinct agents in a cell or a combination of tracing cells that are individually labeled for a single imaging modality (see graphical abstract). All of these combinations have been used in the literature. 
When a combination of cells with individual labels is used, it is assumed that the cells will colocalize and that the different labels do not affect the cells differently. Furthermore, it is possible that label is not taken up uniformly within a cell population, generating mixed results in viability or functionality assays (21), and the possibility that the image data does not reflect the behavior of the majority of nonlabeled cells. Lastly, inadvertent label transfer may occur to nonrelevant cells.

A final factor that can affect image interpretation is the dilution of label with cell division. This will not occur if the cells are labeled in situ, or if a reporter gene is used. However, even with rapidly dividing cells, the number of cell divisions that occur may result in tolerable quantification errors (22). All of these issues must be considered when designing the experimental model.

\subsection{Effects on Cells}

A recent paper (23) discussed the confounding effect that the simple addition of biomaterials, such as contrast agent nanoparticles, can have on standard cytotoxicity assays. This effect occurs owing to the formation of a coating of biomolecules, particularly proteins, on the nanoparticle surface (24), significantly altering the cell medium. The simple aggregation and sinking of label particles can also affect the actual concentration to which the cells are exposed. Other key factors that must be considered are the lifetime of the cell vs the lifetime of the label, viability, in vivo toxicity and clearance and specific effects on cell functionality. Most often the concentration of label added to cells is selected to balance any effects on the cell with maximal label loading.

In addition to the general effects of adding agents, particularly nanoparticles, to cells, specific functional effects can also occur. Several studies have looked into the effect of labeling various cell types with iron oxide agents for MRI, with mixed results on cell viability and functionality. For example, labeling human embryonic stem cells with SPIO had no effect on pluripotency or differentiation capacity compared with nonlabeled controls (25). In this study the amount of iron loading was about $4.5 \mathrm{pg} / \mathrm{cell}$, which is a typical value although the authors used a shorter incubation time and lower SPIO concentration when labeling. The label persisted for 21 days in the cells. Other studies found that labeling with SPIO affected the insulin synthesis in a pancreatic cell line (26), cytokine secretion in macrophages (27) and mobility of neural stem cells $(28,29)$. However, the majority of published data show minimal or no significant effects of labeling with iron oxide on cells, at least on standard assays.

With other imaging modalities, particularly SPECT and PET, the effects of radiation from the agent must also be considered, particularly when labeling long-lived cells such as stem cells $(30,31)$. This is in addition to limitations in the detection time frame owing to the radioactive half-life of the isotope used.

\subsection{Multimodal Imaging in Cellular Therapy}

The role of imaging in cellular therapy has been reviewed elsewhere (1). Clinical cell tracking has generally been done using scintigraphy and SPECT, and more recently with MRI using iron-based labels, although this may be hindered by the recent removal of several MRI contrast agents from the market. FLI, which is the most commonly used 'second' imaging modality in the preclinical world, has limited applicability in humans owing to penetration depth issues. Furthermore, increased cost, imaging time, toxicity and side-effects, the need for more trained personnel and simply the novelty of the techniques has somewhat limited the use of multimodal imaging in clinical cellular therapy.

However, the multitude of preclinical studies now available has demonstrated the necessity for multimodal imaging in optimizing cellular therapy, especially as the field of cellular therapy itself develops and becomes more complex. Figure 1 shows an example of a multimodal imaging of labeled pancreatic islets.

\section{CONSIDERATIONS}

Several assumptions are typically made when imaging labeled cells for in vivo imaging. These are summarized in Table 1, along with the most common strategies used to counter them.

Some agents have been developed and shown to be chemically feasible but have not been tested in vivo or even in cells (see Table 2 for examples). Such testing is especially important when the agents contain heavy metals, which are extremely toxic if released from stabilizing chelates. For example, Gd chelates, commonly used as blood pool agents for MRI contrast, are now indicated as a risk factor for systemic nephrogenic fibrosis (32). Carbon nanotubes and silica nanoparticles, both of which show great promise as preclinical imaging agents, may also have issues owing to long retention times (33).

\section{SUMMARY AND OUTLOOK}

The use of reporter genes revolutionized fluorescence microscopy, as it allows the production of reporters such as a fluorescent protein linked to another gene product or constitutively expressed. Thus, the presence of the reporter product is highly restricted to a specific cell type, is not diluted by cell division (if the gene becomes integrated) and occurs only in viable cells. Luciferase is typically used as a reporter gene product for BLI, and reporter genes have also been developed for MRI. These reporters are typically proteins involved in cellular metal homeostatis, particularly iron storage (34). A recent study used the expression of a metabolically biotinylated luciferase that is membrane bound (6). This construct allowed in vivo $\mathrm{BLI}$, and also targeting of other imaging agents to the membrane-bound biotin using streptavidin-bound Alexa750 (FLI), ${ }^{111}$ In (SPECT) and magnetic nanoparticles (MRI). This approach couples targeting and noninvasive imaging. Such an approach is easily amenable to multimodal imaging, but is restricted to genetically modified cells and subjects on biotindeficient diets. The use of reporter genes for imaging may overcome some of the disadvantages of conventional labels, at least in preclinical models.

It is vital to consider what information is required from the images (localization, viability, functionality or quantification) in order to determine which imaging modality would be most applicable, and if multimodal imaging provides relevant, nonredundant information. The practicality of an imaging scheme must also be considered, in terms of the number of imaging sessions required, cost, imaging time and (repeated, frequent) anesthetic use for preclinical studies. A multimodal imaging study can yield more information per subject, but requires more and longer imaging sessions per subject. For example, simply organizing the logistics can become difficult: in one paper (20), patients received injections of a radioactive tracer for PET after receiving cellular therapy for cancer. The PET tracer 
accumulated in treated lymph nodes, but this presented new problems as some of these patients were also scheduled for lymph node resections, thus potentially exposing the surgical staff to the residual radioactivity. Furthermore, the PET tracer itself had to be prepared and transported from the cyclotron in time for the cell injections, within the usable lifetime of the tracer. These kinds of studies require precise and thorough planning, and can involve over 50 people in the clinic. Despite these issues, PET is a common clinical imaging modality that is now more often being combined with MRI (and has long been combined with CT).

Finally, the addition of specific functionalities to multimodal imaging agents is under development. For example, one agent consists of a iron oxide core with quantum dots functionalized with an anti-cancer agent and a targeting motif (35). In this agent, the quantum dots remain quenched until activated by specific intracellular reactions triggered by drug uptake. Overall, despite the feasibility challenges, in our opinion, multimodal imaging will offer many advantages to guide progress in cellular therapeutics.

\section{Acknowledgements}

This work was supported by the Netherlands Institute of Regenerative Medicine (NIRM, FES0908), the EU FP7 progam ENCITE (HEALTH-F5-2008-201842), the Netherlands Organization for Scientific Research (NWO VENI 700.10.409, VIDI 917.76.363 and Spinoza), the European Research Council (ERC) grant ERC-2010AdG-269019-PATHFINDER and KWF2009-4402.

\section{REFERENCES}

1. Srinivas M, Aarntzen EH, Bulte JW, Oyen WJ, Heerschap A, de Vries IJ, Figdor CG. Imaging of cellular therapies. Adv Drug Deliv Rev 2010;62 (11):1080-1093.

2. Cho JH, Hong KS, Cho J, Chang SK, Cheong C, Lee NH, Kim H, Warren WS, Ahn S, Lee C. Detection of iron-labeled single cells by MR imaging based on intermolecular double quantum coherences at $14 \mathrm{~T}$. J Magn Reson 2012;217:86-91.

3. Gilad AA, Winnard PT, Jr., van Zijl PC, Bulte JW. Developing MR reporter genes: promises and pitfalls. NMR Biomed 2007;20(3):275-290.

4. Srinivas M, Heerschap A, Ahrens ET, Figdor CG, de Vries IJ. (19)F MRI for quantitative in vivo cell tracking. Trends Biotechnol 2010; 28(7): 363-370.

5. Fontanellas A, Hervas-Stubbs S, Sampedro A, Collantes M, Azpilicueta A, Mauleon I, Paneda A, Quincoces G, Prieto J, Melero I, Penuelas I. PET imaging of thymidine kinase gene expression in the liver of non-human primates following systemic delivery of an adenoviral vector. Gene Ther 2009; 16(1): 136-141.

6. Niers JM, Chen JW, Lewandrowski G, Kerami M, Garanger E, Wojtkiewicz G, Waterman P, Keliher E, Weissleder R, Tannous BA. Single reporter for targeted multimodal in vivo imaging. J Am Chem Soc 2012; 134(11): 5149-5156.

7. Barnett BP, Ruiz-Cabello J, Hota P, Ouwerkerk R, Shamblott MJ, Lauzon C, Walczak P, Gilson WD, Chacko VP, Kraitchman DL, Arepally A, Bulte JW. Use of perfluorocarbon nanoparticles for non-invasive multimodal cell tracking of human pancreatic islets. Contrast Media Mol Imag 2011; 6(4): 251-259.

8. Arifin DR, Long CM, Gilad AA, Alric C, Roux S, Tillement O, Link TW, Arepally A, Bulte JW. Trimodal gadolinium-gold microcapsules containing pancreatic islet cells restore normoglycemia in diabetic mice and can be tracked by using US, CT, and positive-contrast MR imaging. Radiology 2011; 260(3): 790-798.

9. Jackson J, Chapon C, Jones W, Hirani E, Qassim A, Bhakoo K. In vivo multimodal imaging of stem cell transplantation in a rodent model of Parkinson's disease. J Neurosci Meth 2009; 183(2): 141-148.

10. Jo MH, Ali BA, Al-Khedhairy AA, Lee CH, Kim B, Haam S, Huh YM, Ko HY, Kim S. A reverse complementary multimodal imaging system to visualize microRNA9-involved neurogenesis using peptide targeting transferrin receptor-conjugated magnetic fluorescence nanoparticles. Biomaterials 2012; 33(27): 6456-6467.
11. De Vocht N, Reekmans K, Bergwerf I, Praet J, Hoornaert C, Le Blon D, Daans J, Berneman Z, Van der Linden A, Ponsaerts P. Multimodal imaging of stem cell implantation in the central nervous system of mice. J Vis Exp 2012; (64): e3906.

12. Misri R, Meier D, Yung AC, Kozlowski P, Hafeli UO. Development and evaluation of a dual-modality (MRI/SPECT) molecular imaging bioprobe. Nanomedicine 2012; 8(6): 1007-1016.

13. Huang $X$, Zhang $F$, Lee $S$, Swierczewska $M$, Kiesewetter DO, Lang $L$, Zhang G, Zhu L, Gao H, Choi HS, Niu G, Chen X. Long-term multimodal imaging of tumor draining sentinel lymph nodes using mesoporous silica-based nanoprobes. Biomaterials 2012; 33(17): 4370-4378.

14. Passuello T, Pedroni M, Piccinelli F, Polizzi S, Marzola P, Tambalo $S$, Conti G, Benati D, Vetrone F, Bettinelli M, Speghini A. PEG-capped, lanthanide doped $\mathrm{GdF}(3)$ nanoparticles: luminescent and $\mathrm{T}(2)$ contrast agents for optical and MRI multimodal imaging. Nanoscale, 2012 Dec 21; 4(24):7682-9. doi: 10.1039/c2nr31796f.Epub 2012 Nov 2.

15. Zhu X, Zhou J, Chen M, Shi M, Feng W, Li F. Core-shell Fe304@NaLuF4:Yb,Er/Tm nanostructure for MRI, CT and upconversion luminescence tri-modality imaging. Biomaterials 2012; 33(18): 4618-4627.

16. Hwang do W, Ko HY, Kim SK, Kim D, Lee DS, Kim S. Development of a quadruple imaging modality by using nanoparticles. Chemistry 2009; 15(37): 9387-9393.

17. Azhdarinia A, Ghosh P, Ghosh S, Wilganowski N, Sevick-Muraca EM. Dual-labeling strategies for nuclear and fluorescence molecular imaging: a review and analysis. Mol Imag Biol 2012; 14(3): 261-276.

18. Guenoun J, Ruggiero A, Doeswijk G, Janssens RC, Koning GA, Kotek $\mathrm{G}$, Krestin GP, Bernsen MR. In vivo quantitative assessment of cell viability of gadolinium or iron-labeled cells using MRI and bioluminescence imaging. Contrast Media Mol Imag 2013; 8(2): 165-174.

19. de Vries IJ, Lesterhuis WJ, Barentsz JO, Verdijk P, van Krieken JH, Boerman OC, Oyen WJ, Bonenkamp JJ, Boezeman JB, Adema GJ, Bulte JW, Scheenen TW, Punt CJ, Heerschap A, Figdor CG. Magnetic resonance tracking of dendritic cells in melanoma patients for monitoring of cellular therapy. Nat Biotechnol 2005; 23(11): 1407-1413.

20. Aarntzen $E H$, Srinivas $M$, De Wilt $J H$, Jacobs JF, Lesterhuis WJ, Windhorst AD, Troost EG, Bonenkamp JJ, van Rossum MM, Blokx WA, Mus RD, Boerman OC, Punt CJ, Figdor CG, Oyen WJ, de Vries IJ. Early identification of antigen-specific immune responses in vivo by [18F]-labeled 3'-fluoro-3'-deoxy-thymidine ([18 F]FLT) PET imaging. Proc Natl Acad Sci USA 2011; 108(45): 18396-18399.

21. Mant A, Chinnery F, Elliott T, Williams AP. The pathway of cross-presentation is influenced by the particle size of phagocytosed antigen. Immunology 2012; 136(2): 163-175.

22. Srinivas M, Turner MS, Janjic JM, Morel PA, Laidlaw DH, Ahrens ET. In vivo cytometry of antigen-specific t cells using (19)F MRI. Magn Reson Med 2009 Sep; 62(3): 747-53. doi: 10.1002/mrm.22063.

23. Laurent S, Burtea C, Thirifays C, Hafeli UO, Mahmoudi M. Crucial ignored parameters on nanotoxicology: the importance of toxicity assay modifications and 'cell vision'. PLoS One 2012; 7(1): e29997.

24. Mahmoudi M, Lynch I, Ejtehadi MR, Monopoli MP, Bombelli FB, Laurent S. Protein-nanoparticle interactions: opportunities and challenges. Chem Rev 2011; 111(9): 5610-5637.

25. Nejadnik H, Henning TD, Castaneda RT, Boddington S, Taubert S, Jha P, Tavri S, Golovko D, Ackerman L, Meier R, Daldrup-Link HE. Somatic differentiation and MR imaging of magnetically labeled human embryonic stem cells. Cell Transplant 2012; 21(12): 2555-67. doi: 10.3727/096368912X653156. Epub 2012 Aug 2.

26. Kim HS, Tian L, Lin S, Cha JH, Jung HS, Park KS, Moon WK. Magnetic labeling of pancreatic beta-cells modulates the glucose- and insulininduced phosphorylation of ERK1/2 and AKT. Contrast Media Mol Imag 2013; 8(1): 20-26.

27. Li M, Kim HS, Tian L, Yu MK, Jon S, Moon WK. Comparison of two ultrasmall superparamagnetic iron oxides on cytotoxicity and $\mathrm{mr}$ imaging of tumors. Theranostics 2012; 2(1): 76-85.

28. Cromer Berman SM, Kshitiz, Wang CJ, Orukari I, Levchenko A, Bulte JW, Walczak P. Cell motility of neural stem cells is reduced after SPIO-labeling, which is mitigated after exocytosis. Magn Reson Med 2013 Jan; 69(1): 255-62. doi: 10.1002/mrm.24216. Epub 2012 Feb 28.

29. de Chickera SN, Snir J, Willert C, Rohani R, Foley R, Foster PJ, Dekaban GA. Labelling dendritic cells with SPIO has implications for their 
subsequent in vivo migration as assessed with cellular MRI. Contrast Media Mol Imag 2011; 6(4): 314-327.

30. Gholamrezanezhad A, Mirpour S, Ardekani JM, Bagheri M, Alimoghadam K, Yarmand S, Malekzadeh R. Cytotoxicity of $111 \mathrm{ln}$-oxine on mesenchymal stem cells: a time-dependent adverse effect. Nucl Med Commun 2009; 30(3): 210-216.

31. Nowak B, Weber C, Schober A, Zeiffer U, Liehn EA, von Hundelshausen P, Reinartz P, Schaefer WM, Buell U. Indium-111 oxine labelling affects the cellular integrity of haematopoietic progenitor cells. Eur J Nucl Med Mol Imag 2007; 34(5): 715-721.

32. Gupta A, Shamseddin MK, Khaira A. Pathomechanisms of nephrogenic systemic fibrosis: new insights. Clin Exp Dermatol 2011; 36(7): 763-768.
33. Longmire M, Choyke PL, Kobayashi H. Clearance properties of nanosized particles and molecules as imaging agents: considerations and caveats. Nanomedicine (Lond) 2008; 3(5): 703-717.

34. Vandsburger MH, Radoul M, Cohen B, Neeman M. MRI reporter genes: applications for imaging of cell survival, proliferation, migration and differentiation. NMR Biomed 2013 Jul; 26(7): 872-84. doi: 10.1002/nbm.2869. Epub 2012 Dec 6.

35. Mitra RN, Doshi M, Zhang X, Tyus JC, Bengtsson N, Fletcher S, Page BD, Turkson J, Gesquiere AJ, Gunning PT, Walter GA, Santra S. An activatable multimodal/multifunctional nanoprobe for direct imaging of intracellular drug delivery. Biomaterials 2012; 33(5): $1500-1508$. 